\title{
In the Night of Hallucinations the Cheetah Stalks
}

In the night of hallucinations

The inhuman, timeless beauty of desires stands straight.

Magnificence stirs like leaves in wicked silence.

The starlight and the forest of self-delusion are unending;

Here you move, black cheetah,

Here you move within sparks and your animal smell.

Here the elemental rain, the thunder of the absolute.

Here the slow, dry beat of existence spreads over summer's soil.

Here the winter of God'd leafless grace.

And between the tropics of involvement and uninvolvement

Your body and mine wander over thousands of miles ...

Each muscle of mine charged

In the night of hallucinations.

The blind glories of blood pooling

In your memory.

In the eyes the stormy traffic of zodiacs, the cycles of seasons,

And throughout the forest, in the mad heat,

Blows the wind of your animal smell.

Black wildcat in darkness, in moonlight.

Black wildcat pouncing out of the leaves.

Black wildcat in heat, in the smell of incense.

Black wildcat in the beastly fragrance of spring.

Black wildcat over dry leaves in winter.

Black wildcat surrounded by the monsoon, hot in the cave.

Black wildcat our naked combat in the unknown.

And below us the warm, darkening ground,

Ploughed. The whole world a merciful, detached forest

Under our savage loving.

Translated by the author and Mick Fedullo 